\title{
Effect of boron promotion on coke formation during propane dehydrogenation over $\mathrm{Pt} / \mathrm{Y}-\mathrm{Al} 203$ catalysts
}

\author{
M. Aly, Laboratory for Chemical Technology, Ghent University \\ E. Fornero, Instituto de Desarrollo Tecnológico para la Industria Química, CONICET/UNL \\ J.E. De Vrieze, V. Galvita, M. Saeys, Laboratory for Chemical Technology, Ghent University
}

\section{Introduction:}

Coke formation continues to be an important challenge for Pt-based catalysts during propane dehydrogenation $(\mathrm{PDH})^{1}$. Boron promotion drastically reduces coke formation on nickel ${ }^{2}$ during $^{2}$ steam reforming and on cobalt ${ }^{3}$ during Fischer-Tropsch synthesis. DFT calculations and catalyst characterization indicate that reduced boron atoms selectively block step and/or subsurface sites, thus preventing nucleation and growth of deactivating carbon ${ }^{2,3}$.

In this work, boron is introduced to enhance the catalytic performance of $\mathrm{Pt} / \mathrm{\gamma}-\mathrm{Al}_{2} \mathrm{O}_{3}$ catalysts during PDH. A series of catalysts with different boron loadings was prepared following various impregnation sequences. Detailed characterization and DFT calculations help identify boron's location and state (alloy/amorphous oxide).

\section{Results:}

XB- $\gamma-\mathrm{Al}_{2} \mathrm{O}_{3}$ support materials $(\mathrm{X}=\mathrm{wt} . \% \mathrm{~B})$ were prepared via wet impregnation of $\mathrm{H}_{3} \mathrm{BO}_{3}$ onto commercial $\gamma-\mathrm{Al}_{2} \mathrm{O}_{3}$. Three different synthesis routes were followed: (a) $\mathrm{Pt} / \mathrm{XB}-\mathrm{\gamma}-\mathrm{Al}_{2} \mathrm{O}_{3}$ catalysts were prepared via wet impregnation of $\mathrm{H}_{2} \mathrm{PtCl}_{6}$ onto $\mathrm{XB}-\mathrm{\gamma}-\mathrm{Al}_{2} \mathrm{O}_{3}$. (b) $1 \mathrm{~B} / \mathrm{Pt}-\mathrm{\gamma}-\mathrm{Al}_{2} \mathrm{O}_{3}$ was prepared via wet impregnation of $\mathrm{H}_{3} \mathrm{BO}_{3}$ onto $\mathrm{Pt} / \mathrm{\gamma}-\mathrm{Al}_{2} \mathrm{O}_{3}$ i.e., an inverse sequential impregnation. (c) $\mathrm{Pt}-1 \mathrm{~B}-\mathrm{\gamma}$ $\mathrm{Al}_{2} \mathrm{O}_{3}$ was prepared by co-impregnation. $\mathrm{Pt} / \mathrm{Y}-\mathrm{Al}_{2} \mathrm{O}_{3}$ was prepared as a reference. The platinum loading was fixed at 3wt.\% to facilitate characterization and obtain B/Pt (mol) ratios from 1-10.

Effects of boron loading and impregnation sequence were investigated during short-term (20 min) PDH tests at $600^{\circ} \mathrm{C}$ and a $\mathrm{C}_{3} \mathrm{H}_{8} / \mathrm{H}_{2}$ ratio of one. Unlike with nickel and cobalt, 2,3 the promoting effect of boron was only observed when boron was introduced before the active metal. The Pt/1B- $\gamma$ $\mathrm{Al}_{2} \mathrm{O}_{3}$ catalyst showed only a minor reduction in activity during the short-term experiment but achieved a 2.6-fold reduction in the amount of deposited carbon for an optimal loading of $1 \mathrm{wt} . \%$ B. Long-term experiments ( $12 \mathrm{hr}$ ) confirmed the improved stability and selectivity of Pt/1B- $\gamma-\mathrm{Al}_{2} \mathrm{O}_{3}$, (Fig. 1a) with a 3.2-fold reduction in deposited carbon and an increase in propylene selectivity from 92 to $98 \%$. TPO-profiles (Fig.1b) of spent catalysts show that boron promotion eliminates and reduces the low- and high-temperature carbon oxidation peaks, respectively. Propylene decomposition experiments on pure and boron-modified $\mathrm{y}-\mathrm{Al}_{2} \mathrm{O}_{3}$ relate the low-temperature peak to carbon formed on the support.

$\mathrm{NH}_{3}$-TPD experiments indicate that boron modifies the number and strength of the support acid sites. In-situ XRD experiments under $\mathrm{H}_{2}$ at $600^{\circ} \mathrm{C}$ exclude the formation of a Pt-B alloy. TEM-EDS shows a uniform distribution of boron over the material. DFT calculations support the formation of boron oxide rather than a Pt-B alloy. Testing and characterization thus indicate that boron modifies both the active-metal and the support. Clearly, the promoting effect of boron is more complex than often assumed ${ }^{4}$.
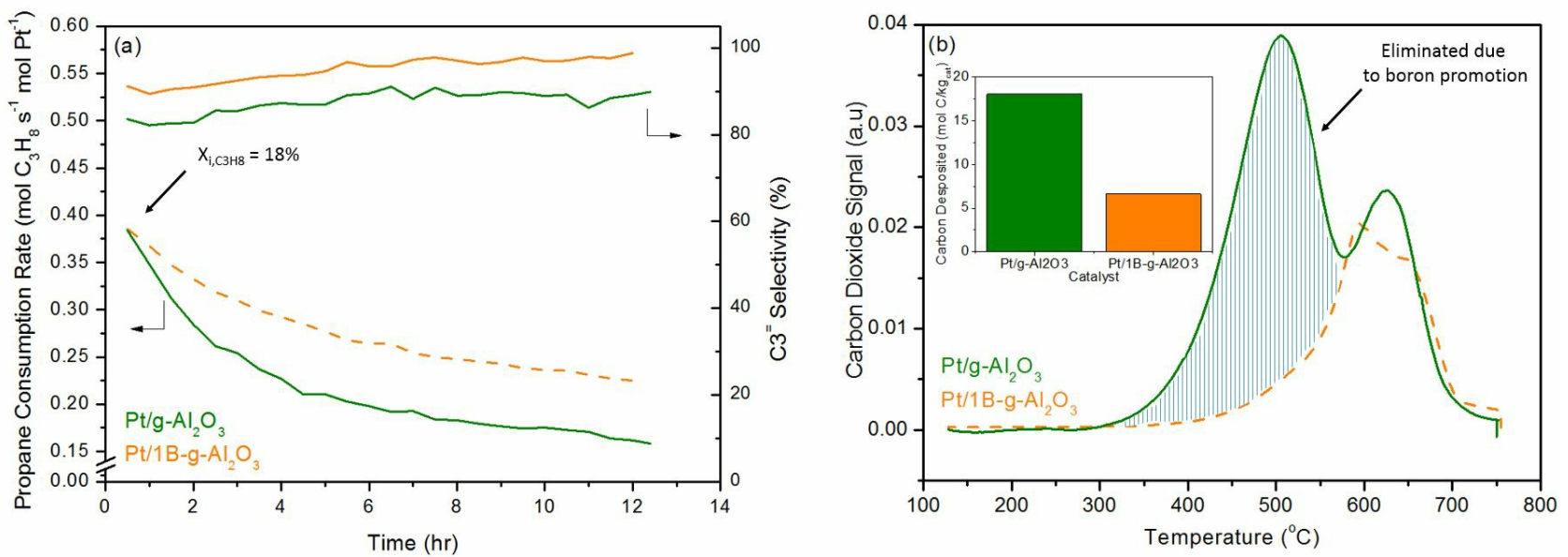

[1] J. J. H. B. Sattler, J. R. Martinez, E. S. Jimenez, B. M. Weckhuysen. (2014). Chem. Rev., 20, 10613. DOI: $10.1021 / \operatorname{cr} 5002436$

[2] J. Xu, L. Chen, K. Tan, A. Borgna, M. Saeys. (2009). J. Catal., 2, 158. DOI: 10.1016/i.jcat.2008.11.007

[3] K. Tan, J. Chang, A. Borgna, M. Saeys. (2011). J. Catal., 1, 50. DOI: 10.1016/j.jcat.2011.03.002

[4] M. Ha, E. T. Baxter, A. C. Cass, S. L. Anderson, A. N. Alexandrova. (2017). J. Am. Chem. SoC., 33, 11568. DOI: $\underline{10.1021 / \mathrm{iacs} .7 \mathrm{~b} 05894}$ 